\title{
"En todas las dictaduras siempre hay espacios de resistencia frente a la opresión" ". A atuação dos movimentos pela anistia e o controle e vigilância do regime civil-militar (1975-1983)
}

\section{Resumo}

O objetivo desse artigo é analisar a vigilância e controle de parte da comunidade de informações e segurança aos movimentos pela anistia no contexto da chamada distensão política. Isso porque, as demandas dessas entidades, com destaque para o Movimento Feminino pela Anistia (MFPA) e o Comitê Brasileiro pela Anistia (CBA), estavam concentradas em questões muito sensíveis para o regime, mesmo em tempos de abertura política. Ao denunciarem publicamente, no Brasil e no exterior, os crimes da ditadura e exigirem o desmantelamento do aparelho repressivo, além do fim das leis discricionárias, esses movimentos atingiam não apenas o alto escalão militar, comprometidos com uma abertura que fosse lenta, gradual e segura, mas também setores no interior das Forças Armadas claramente insatisfeitos com o espaço de atuação da oposição civil organizada naquele momento. Nesse contexto, a luta dos movimentos pela anistia corroborava, na perspectiva dos militares, a necessidade de constituir uma vigilância cerrada aos opositores ou possíveis opositores do regime. A análise da relação entre a vigilância do Estado e a atuação dos movimentos pela anistia precisa levar em consideração, portanto, os limites da chamada abertura lenta, gradual e segura cujas práticas guardam muitas continuidades em relação ao período anterior, além de trazer à tona os dissensos no interior das Forças Armadas e a atuação e capacidade mobilizatória das entidades de luta pela anistia. Para tanto, utilizaremos documentos do DEOPS/SP e SNI.

Palavras-chave: Vigilância. Militares. Anistia. Polícia Política.

Transição democrática.

\author{
Pâmela de Almeida Resende \\ Mestra em História pela \\ Universidade Estadual de Campinas \\ (UNICAMP). Consultora da \\ Comissão de Anistia desde \\ Junho/2013 onde realiza pesquisa \\ histórica para a Comissão Nacional \\ da Verdade \\ pamelaresende@yahoo.com.br
}

\section{Para citar este artigo:}

RESENDE, Pâmela de Almeida. "En todas las dictaduras siempre hay espacios de resistencia frente a la opresión". A atuação dos movimentos pela anistia e o controle e vigilância do regime civilmilitar (1975-1983). Revista Tempo e Argumento, Florianópolis, v. 5, n.10, jul./dez. 2013. p. 207 - 233.

\section{DOI: $10.5965 / 2175180305102013207$}

http://dx.doi.org/10.5965/2175180305102013207

\footnotetext{
${ }^{1}$ Memoria Abierta. Testimonio de Josefina Ludmer. Buenos Aires, 2012.
} 
"En todas las dictaduras siempre hay espacios de resistencia frente a la opresión". The action of the movements for amnesty and the control and supervision of the civil and military regime (19751983)

\begin{abstract}
The aim of this paper is to analyze the surveillance and control of the information security and the amnesty movement community within the called political détente. This is because the demands of those entities, particularly the Female Movement for Amnesty (MFPA) and the Brazilian Amnesty Committee (CBA), which were concentrated in the most sensitive issues for the regime even in times of political openness. By publicly denouncing, in Brazil and abroad, the crimes of dictatorship; and to demand the dismantling of the repressive apparatus besides the end of discretionary laws, these movements not only reached the high ranking military committed to an opening that was slow, gradual and safe, but also sectors within the military, clearly dissatisfied with the mobilization performance of the organized civilian opposition at that time. In this context, the movements' struggle for amnesty corroborated, in the perspective of the military, the need to establish tight surveillance on opponents or potential opponents of the regime. The analysis of the relationship between state surveillance and the performance of the amnesty movement must take into account, therefore, limits of the so called slow, gradual and safe opening practices that often seem to continue after the previous period, and bring up dissension within the Armed Forces and the mobilizing performance and ability of entities in the struggle for amnesty. We used documents from DEOPS / SP and SNI.
\end{abstract}

Keywords: Surveillance. Military. Amnesty. Political Police. Democratic transition. 
Com o golpe civil-militar, em 1964, os militares empreenderam a organização de um complexo aparato de segurança e informações que vigiava e reprimia os movimentos e/ou indivíduos que fizessem oposição à ordem estabelecida. Além disso, tornava-se necessário, a reiteração da noção de que o país estava dominado por "maus cidadãos", "o que evidencia que as práticas mais aberrantes estavam institucionalizadas e foram cometidas por agentes doutrinados para cometê-las, e não se trataram de atos isolados de indivíduos sádicos" (BAUER, 2011, p. 53). Para os militares, vivia-se uma guerra revolucionária e ideológica que, de modo geral, significava considerar como inimigo todo e qualquer grupo que fizesse oposição ao regime. Nesse contexto de necessidade de obter um número cada vez maior de informações sobre aqueles considerados opositores ou possíveis opositores, foi criado o Serviço Nacional de Informações (SNI). Instituído já em 1964, esse órgão inaugurou a chamada "comunidade de informações" do regime e tinha por finalidade "superintender e coordenar, em todo território nacional, as atividades de informação e de contrainformação, em particular as que interessem à Segurança Nacional”. (http://www.planalto.gov.br/ccivil_03/LEIS/L4341.htm Texto da Lei $\mathrm{n}^{\circ} 4.341$ de 13 de junho de 1964. Acessado em: 30/08/2013)

O SNI foi estruturado basicamente por três instâncias: a chefia, a Agência Central e as agências regionais criadas em alguns estados da Federação. Além disso, compreendia uma seção de informações estratégicas, uma seção de segurança interna e uma seção de operações especiais. Contava, ainda, com as Assessorias de Segurança e Informações (ASIs) e as Divisões de Segurança e Informações (DSIs) que atuavam como órgãos complementares. No interior de toda essa estrutura, foi incorporado também o Serviço Federal de Informação e Contra-Informação (SFICI) que havia sido criado no final do governo de Juscelino Kubitschek ${ }^{2}$.

\footnotetext{
${ }^{2}$ Segundo Priscila Carlos Brandão Antunes: "A partir de 1956, com o acirramento da Guerra Fria, a atividade de informações passou a receber um novo tratamento por parte das autoridades governamentais. Foi quando o presidente Juscelino Kubitschek indicou o general Humberto Melo para ativar o SFICI. De acordo com o depoimento do general Rubem Denys, que juntamente com o general Humberto Melo foi um dos responsáveis pela ativação desse órgão, haveria um compromisso do governo brasileiro com o governo americano de se criar um serviço nos moldes da CIA (Central Intelligence Agency). A criação de uma agência de informações no Brasil fazia parte de uma estratégia de fortalecimento das estruturas dos estados integrantes da OEA (Organização dos Estados Americanos) que era de extremo interesse para o governo americano. Este, além de prestigiar sua criação, teria dado todo o apoio e assistência necessários à construção da agência no Brasil”. ANTUNES, Priscila C. B. SNI \& Abin: uma leitura da
} 
De fato, o SNI ao mesmo tempo em que mantinha, em alguma medida, as informações centralizadas, possuía também um significativo controle em outros pontos do território, principalmente nas capitais, por conta das agências regionais e de instituições públicas que repassavam informações. Segundo afirma Carlos Fico,

Tratava-se de uma necessidade de informações que ultrapassava a indispensável alimentação do sistema de tomada de decisões presidenciais e atingia a auscultação da esfera particular da vida dos cidadãos. Afinal, a noção de 'guerra revolucionária' ou 'guerra interna' pressupunha que alguns brasileiros fossem 'inimigos de guerra' do regime: ora, contra o inimigo, todas as armas deveriam ser utilizadas, inclusive as de efeito moral ou psicológico. Assim, saber detalhes sobre a vida sexual de alguém era inútil, como informação, para as decisões governamentais; mas poderia ser essencial para as atividades clandestinas de espionagem do sistema, que poderia - como efetivamente fez - lançar mão de tais dados para desqualificar o 'inimigo'. (FICO, 2001, p. 76)

No final da década de 1970, já no governo de João Figueiredo, o que se verificou foi uma expansão das atividades do SNI que tinha se transformado numa espécie de quarta força armada (D’ARAÚJO; SOARES; CASTRO, 1995, p. 117), tamanho era o seu poder, mesmo em tempos de abertura política. O chefe desse órgão durante o governo de Figueiredo era o general Octávio Medeiros com a Agência Central sob comando do general Newton Cruz. Medeiros atuou sob amplo apoio do presidente que lhe concedeu todos os recursos humanos, materiais e financeiros necessários para o atendimento das necessidades do órgão (ANTUNES, 2002, p. 59). Portanto, é necessário ter em vista que, longe de ficar restrito à função de fornecer informações ao presidente da República, o SNI estava orientado pela "lógica da suspeição", já que partia do pressuposto de que todos poderiam ser culpados de subversão.

Assim como os demais órgãos de informações subordinados às Forças Armadas $\left(\mathrm{CISA}^{3}, \mathrm{CENIMAR}^{4}\right.$ e $\left.\mathrm{CIE}^{5}\right)$, as Delegacias de Ordem Política e Social (DOPS) e o

\footnotetext{
atuação dos serviços secretos brasileiros ao longo do século XX. Rio de Janeiro: FGV, 2002, págs. 45-6.

${ }^{3}$ Conhecido inicialmente como "Núcleo do Serviço de Informações e Segurança da Aeronáutica (N-Sisa), o CISA foi reformulado em 1970 passando a se chamar Centro de Informações da Aeronáutica.

${ }^{4}$ Criado no ano de 1957, o CENIMAR teve suas funções redimensionadas durante o período ditatorial.

${ }^{5}$ Criado no ano de 1967.
} 
Departamento de Ordem Política e Social (DEOPS/SP) ${ }^{6}$ foram incorporados à estratégia vigilante e repressiva do regime. Mesmo com as diferentes denominações que recebeu ao longo de sua história, as práticas do DOPS eram comuns, o que envolvia o monitoramento e repressão àqueles considerados "inimigos" do regime, lançando mão de práticas violentas e ilegais, ou mesmo de métodos amparados na legislação (AQUINO; MATTOS; SWENSSON, 2001, p. 24). Dessa maneira, tal órgão tinha por objetivo não apenas punir, mas também prevenir, investigar, vigiar e ameaçar. O objetivo, como é possível supor, era a manutenção da “ordem" através da contenção das manifestações de oposição ao governo.

Segundo os pesquisadores do CPDOC, havia a ideia de que "via controle policial e militar, a sociedade poderia ser moldada de uma forma estática e desideologizada" (D'ARAÚJO; SOARES; CASTRO, 1994, p. 24). Essa concepção justificava, portanto, a constituição e o funcionamento da comunidade de informações e segurança. Com os movimentos pela anistia não seria diferente, mesmo em tempos de abertura política. Ao denunciarem, como tantos outros movimentos sociais da época, a prática da tortura e as sucessivas violações dos direitos humanos, também entraram para a lista dos opositores do regime. Como exemplo, um documento produzido pelo CIE, em 1978, de 66 páginas, nos fornece um demonstrativo das percepções desse órgão sobre os significados da luta pela anistia naquele momento. Na seção “Considerações Finais”, o agente afirma:

O Movimento pela Anistia constitui-se, na atualidade, num 'PÓLO DE AGLUTINAÇÃO' da totalidade das tendências de esquerda, de contestação e de oposição observando-se, entre elas, um CONSENSO quase generalizado, de imprimirem um 'RUMO COMUM' à ORIENTAÇÃO GERAL peculiar a cada uma delas. (ACE 114085/78. Fundo SNI. Arquivo Nacional)

O conteúdo de parte deste documento apresenta a preocupação do regime com a atuação dos movimentos pela anistia e a rede de movimentos sociais formada em torno

\footnotetext{
${ }^{6}$ Essa sigla faz referência à última denominação que recebeu pela legislação que alterou sua constituição, em 1975, passando a se chamar Departamento de Ordem Política e Social. Tal órgão foi criado pela Lei $n$. 2.034, de 30 de dezembro de 1924, quando recebeu o nome de Delegacia de Ordem Política e Social (DOPS), sendo extinto pelo Decreto n. 20.728, de 04 de março de 1983. Ver: AQUINO, Maria Aparecida de; LEISTER FILHO, Adalberto; MATTOS, Marco Aurélio Vannucchi L. de; SWENSSON JR., Walter Cruz. (org.). A alimentação do Leviatã nos planos regional e nacional: mudanças no DEOPS/SP no pós-1964. Família 50. São Paulo: Arquivo do Estado; Imprensa Oficial, 2002. p. 22.
} 
dessa demanda. A partir, então, do controle das informações acerca das práticas daqueles setores e entidades que vai se centrar a "lógica da suspeição". Como atesta a continuação do documento citado acima,

Nesse sentido, ressalta-se uma acentuada hegemonia do Partido Comunista Brasileiro no processo, embora a LIGA OPERÁRIA - LO organização alinhada com as 'concepções políticas' da 'Tendência Proletária da IV Internacional' agora, ao que tudo indica, trasmudada em 'Partido Socialista de Trabalhadores (PST)' tenha desenvolvido (e vem desenvolvendo) diligente esforço no sentido de influenciar o comportamento das diversas facções e de conquistar significativo espaço político. (ACE 114085/78. Fundo SNI. Arquivo Nacional)

Para a lógica do Estado autoritário, os movimentos pela anistia eram vistos como lugares de discussão e articulação política, mas, sobretudo, de infiltração e disseminação de ideias consideradas "subversivas". Essa concepção ocasionou a produção de extensos dossiês, no DEOPS/SP e no SNI, com informações que dão conta das relações existentes entre os grupos e pessoas reunidas em torno da bandeira da anistia e dos partidos de oposição ao regime. Logo, ao mesmo tempo em que as forças oposicionistas lutavam por espaço, a comunidade de informações e segurança do regime reforçava, por meio da vigilância diária e constante, a ideia de que as ações empreendidas levavam em consideração a defesa do Estado e da família brasileira ameaçada pelo comunismo.

Com efeito, não há surpresa nessa constatação, já que isto se justificaria pela retomada, a partir de 1977, dos movimentos sociais que se articulavam segundo demandas diversas. Nesse sentido, houve a preocupação com a construção e preservação da imagem dos governos de Ernesto Geisel e João Figueiredo enquanto símbolos da transição rumo a um novo tempo, ao mesmo tempo em que houve uma forte preocupação com a perda do controle sobre este processo, resultando, então, na necessidade de acompanhar de perto os grupos de contestação ao regime reorganizados naquele momento. Para Carlos Fico,

Embora a 'distensão política' e as eleições, segundo a comunidade de segurança, tivessem servido para ampliar o 'campo de ação para as forças subversivas', na verdade, em meados dos anos 70, as organizações comunistas clandestinas adeptas da luta armada já estavam derrotadas. Assim, era indispensável, para os setores repressivos, encontrar novos inimigos. No contexto da distensão política, o caminho encontrado por tais setores foi acusar o enquistamento de membros do PCB no partido 
de oposição, o MDB, que assim se tornou a 'bola da vez'. Muito atuou, nessa fase, o CIE, que preparou, em 1975, um longo documento estabelecendo conexões entre o MDB e o PCB (municiando, pois, os setores de segurança com motivos para prisões) (FICO, 2001, p. 134).

Nesse contexto, os movimentos pela anistia, sobretudo o Movimento Feminino pela Anistia (MFPA) e o Comitê Brasileiro pela Anistia (CBAs), também se tornaram alvo de vigilância e controle policial. Essa problemática está centrada no fato de que, as demandas dos movimentos que lutavam pela anistia, na década de 1970, estavam diretamente relacionadas a questões e práticas com as quais o regime não se mostrava disposto a colaborar, como: a localização dos mortos e desaparecidos, o desmantelamento da comunidade de informações e segurança; a restauração do habeas corpus; a libertação dos presos políticos, o retorno dos exilados, entre outras. Portanto, o modo como se deu a aprovação da lei $6.683 / 79^{7}$, chamada Lei de Anistia, não significou o encerramento da demanda por justiça proveniente dos amplos setores atingidos pelo regime, incluindo os grupos que, num quadro de fortalecimento das lutas democráticas ${ }^{8}$, reivindicavam uma anistia que fosse ampla, geral e irrestrita. A partir das pesquisas e cruzamentos realizados com a documentação do DEOPS/SP e SNI foi possível mapear os tipos de documentos produzidos no interior desses órgãos, e as temáticas/focos de investigação que estiveram sob o constante olhar vigilante.

\footnotetext{
${ }^{7}$ No dia 28 de agosto de 1979 foi aprovada a Lei 6683 conhecida como Lei de Anistia. De acordo com o texto final: "Art. $1^{\circ}$ É concedida anistia a todos quantos, no período compreendido entre 2 de setembro de 1961 e 15 de agosto de 1979, cometeram crimes políticos ou conexos com estes (...) $1^{\circ}$ Consideram-se conexos, para efeitos deste artigo, os crimes de qualquer natureza relacionados com crimes políticos ou praticados por motivação política. $\S 2^{\circ}$ Excetuam-se dos benefícios da anistia os que foram condenados pela prática de crimes de terrorismo, assalto, sequestro e atentado pessoal". http://www.planalto.gov.br/ccivll_03/Leis/L6683.htm. Verificado em 29/08/2013.

${ }^{8}$ De acordo com Maria Paula Araújo, a luta pela anistia está inserida no contexto das lutas democráticas da segunda metade da década de 1970. Isso porque, a partir da entrada em cena de novos atores políticos com suas respectivas bandeiras, a questão da anistia vai aparecer como a grande força mobilizadora e de articulação entre esses movimentos. Para essa autora é necessário ressaltar, ainda, que "(...) não devemos deixar de lembrar que essa frente democrática não era exatamente uma frente de partidos e organizações de esquerda. Pela simples razão de que tais partidos e organizações eram clandestinos. As esquerdas atuavam nessa - algumas vezes a lideravam - frente que, na verdade, era um conjunto de forças sociais, de entidades representativas de grupos e movimentos sociais; alguns mais radicais, outros de orientação mais moderada". Ver: ARAÚJO, Maria Paula do Nascimento. "Lutas democráticas contra ditadura". In: FERREIRA, Jorge (org.). Revolução e democracia (1964 - ...). Rio de Janeiro: Civilização Brasileira, 2007, p. 343.
} 
Desse modo, no conjunto de documentos analisados, além dos relatórios de informantes, agentes infiltrados, pedidos de busca, informes, etc, encontramos algumas análises que, de modo geral, buscavam fazer um levantamento da campanha pela anistia no Brasil. Pelo menos quatro órgãos diferentes produziram verdadeiros dossiês sobre a atuação na cena pública desses grupos e sua capacidade mobilizatória. Em 25 de janeiro de 1978, num contexto em que os CBAs ainda não haviam sido criados, a Agência Central do SNI com difusão para boa parte de suas agências ${ }^{9}$ produziu um documento ${ }^{10}$ composto apenas de anexos provenientes da Divisão de Segurança e Informações do Ministério da Justiça (DSI/MJ) e do DEOPS/SP. A intenção era chamar atenção para as atividades do MFPA no decorrer do ano de 1977, mas, sobretudo, para a figura de Therezinha Zerbini, fundadora dessa entidade ainda em 1975:

Nos últimos meses tem-se verificado um aumento de atividades do MOVIMENTO FEMININO PELA ANISTIA (MFPA), liderado por TEREZINHA ZERBINI. Os eventos promovidos pelo MFPA ocorrem notadamente nas principais capitais e suas líderes têm procurado o apoio não só de entidades e personalidades costumeiramente contestadoras, como também o suporte de órgãos do governo, principalmente do Poder Legislativo. (ACE 4386/80. Fundo SNI. Arquivo Nacional)

A partir daí, o agente prossegue elencando os eventos que contaram com participações de membros do MFPA, finalizando com o informe que, em dezembro daquele ano, aconteceria em São Paulo um culto ecumênico "às 17,00 horas, na Igreja N. S. de SION, em SÃO PAULO”. Sem tecer maiores considerações acerca do caráter do culto, o anexo na sequência do documento é justamente um relatório produzido pelo DEOPS/SP e intitulado “Celebração Ecumênica dos Direitos Humanos, em homenagem ao Dia da Justiça". Com efeito, a vigilância a solenidades como essa talvez não fossem objeto de destaque caso esses órgãos já não estivessem atentos para os contatos estabelecidos por Zerbini, além do caráter da celebração: a luta pelos direitos humanos. Nesse caso, os pronunciamentos giraram em torno da igualdade entre as pessoas e o combate a miséria destacando, ainda, a inserção de Zerbini nesse ambiente.

\footnotetext{
${ }^{9} \mathrm{ABE}, \mathrm{ABH}, \mathrm{ACG}, \mathrm{ACl}, \mathrm{AFZ}, \mathrm{AMA}, \mathrm{APA}, \mathrm{ARE}, \mathrm{ARJ}, \mathrm{ASP}, \mathrm{ASV}$ NAGO/SNI.

${ }^{10}$ ACE 4386/80. Fundo SNI. Arquivo Nacional.
} 
Outro documento produzido também no ano de 1978 pela Divisão de Segurança e Informações do Ministério da Justiça (DSI/MJ) não traz informações dos eventos em que integrantes dos movimentos de anistia estiveram, mas sim uma análise extremamente detalhada do caráter da campanha pela anistia no Brasil com destaque para: “1) Os princípios que regem a anistia. 2) O momento histórico em que a anistia é reivindicada. 3) os prováveis efeitos da concessão da anistia no BRASIL hoje". De modo que, a partir desses três pontos o analista procurou chamar atenção para a anistia como uma medida importante, já que na sua visão ajuda a assegurar a "cordialidade”, "o perdão" e "uma vida tranquila e sem rancores", pois:

A anistia em si é uma medida profundamente simpática. Traz a nosso espírito impressões que só o podem encantar: situação nacional firme e sadia, em que a criminalidade política é firmemente condenada pelo alto nível cívico e moral da população; prisioneiros arrependidos e sequiosos de retomar um lugar entre os cidadãos observantes da lei e da ordem, bem como um trabalho honesto para ajudar a manutenção da família e do progresso do País; cárceres que se abrem; famílias que recebem com afeto transbordante entes queridos dos quais estavam separadas, e sobretudo - inocentes injustiçados que recuperam a dignidade da vida e a liberdade a que tinham direito, queixas que se perdoam e se esquecem de lado a lado. Uma grande festa de reconciliação nacional, enfim. (BR.AN.RIO.TT.o.MCP.PRO.1245. Fundo DSI/MJ. Arquivo Nacional)

Percebe-se, a partir dessas considerações, que se a anistia ajudaria a "integrar a família brasileira", isso só ocorreria a partir do desarmamento dos espíritos de cidadãos arrependidos de seus atos e dispostos a viverem numa sociedade conciliada. No entanto, para os movimentos de anistia, principalmente os CBAs, não seria possível seguir adiante sem as reparações necessárias, o que representou um dissenso e embate de concepções diferentes de anistia e que iria marcar de maneira decisiva o processo de abertura política. Assim, para esse mesmo analista a anistia nos termos em que reivindicavam os movimentos "assumiria, nesse contexto, o aspecto da ruptura de um dique que represa a subversão". Era necessário, então, manter a distensão dentro dos limites estabelecidos pelo governo a despeito dos espaços cada vez mais diversos ocupados pelos movimentos pela anistia.

Ainda em 1978, o Centro de Informações do Exército produziu um relatório de 66 páginas dedicadas apenas à luta pela anistia. Com difusão para os outros órgãos das 
Forças Armadas - CISA $^{11}$ e CENIMAR -, além da Agência Central do SNI, o documento é basicamente um registro cronológico das atividades do MFPA e, posteriormente, dos CBAs na cidade de São Paulo naquele ano. Para o analista,

(...) a síntese dos fatos apresentados revela a intenção proposital, dirigida e orientada no sentido de, lenta e persistentemente, criar, no seio da população, a imagem de um 'REGIME DITATORIAL', pela negação da 'LEGITIMIDADE DO PODER' e pela caracterização da 'OPRESSÃO E VIOLÊNCIA. (ACE 114085/78. Fundo SNI. Arquivo Nacional)

Dessa maneira, o autor do documento pontuou, por exemplo, a reunião realizada em 20 de março, no Teatro Ruth Escobar, que aprovou a criação de um movimento pela anistia em caráter nacional visando "congregar todos os setores e comitês já existentes na luta pela Anistia". ${ }^{12}$ Destacou, ainda, os pronunciamentos feitos por pessoas de diversas entidades, mostrando a perspectiva de articulação da luta pela anistia com outros setores, além do apoio internacional ${ }^{13}$ não apenas para a causa da anistia, mas também para a denúncia do regime civil-militar no exterior.

Já no ano de 1979, após a aprovação da Lei de Anistia, a Agência Central do SNI produziu um documento ${ }^{14}$ ressaltando de maneira pontual alguns marcos na luta pela anistia, além de afirmar que movimentos como MFPA e CBAs "caracterizam-se por exercer intensa atividade contestatória ao Governo e ao regime". Não há muita novidade nessa afirmativa, tendo em vista que todos esses relatórios, além daqueles dedicados a algum evento específico, de alguma maneira procuravam deixar claro o caráter da oposição representada por esses movimentos. Apesar de não destacar, como no documento anterior, as reuniões e encontros que levaram a uma articulação dos setores envolvidos na luta pela anistia, o informante não deixou de pontuar que o MFPA,

\footnotetext{
${ }^{11}$ No acervo da Aeronáutica, encontramos o mesmo documento encaminhado para "EMAER-A2, I, II, III e IV COMAR-COMCOS. BR.AN.VAZ.65.15. Fundo Aeronáutica. Arquivo Nacional.

${ }^{12}$ ACE $114085 / 78$, p. 8. Fundo SNI. Arquivo Nacional.

13 Para destacar essa articulação dos movimentos pela anistia no Brasil com as entidades de direitos humanos no exterior, o analista vai destacar alguns pronunciamentos, como o de Ruth Escobar por ocasião de uma reunião em 27 de março de 1978. Segundo o documento: “c. RUTH ESCOBAR '...chegara de viagem do exterior naquela data e que durante a mesma estivera em contato com a totalidade dos Movimentos Internacionais Pela Anistia, solicitando-lhes que trabalhassem em apoio ao Movimento Brasileiro pela Anistia"”. ACE 114085/78, p. 49. Fundo SNI. Arquivo Nacional.

${ }^{14}$ ACE 4214/79. Fundo SNI. Arquivo Nacional.
} 
antes da criação dos CBAs, “conseguia aglutinar representantes de setores contestatórios ao Governo, notadamente no meio artístico, intelectual, estudantil, do clero progressista, de profissionais liberais, de trabalhadores e de ativistas de esquerda". Além disso, chamou atenção para a centralidade e destaque do I Congresso Nacional pela Anistia, realizado em novembro de 1978 e para a conjuntura pós Lei de Anistia ao afirmar que:

Após a sanção da Lei da Anistia, que não atendeu à principal reivindicação dos movimentos, que era a anistia total, estes passaram a exaltar subversivos por ocasião do seu retorno ao País, ou quando eram postos em liberdade os que se encontravam presos. Atualmente, estão se manifestando publicamente para homenagear os terroristas mortos em confronto com os órgãos de segurança. Nessas ocasiões, os terroristas são apresentados como heróis, conforme ocorreu no último dia 18 Set, por ocasião do aniversário da morte de CARLOS LAMARCA. Como essas manifestações não estão obtendo repercussão na massa, os movimentos de anistia vêm pressionando a OAB para que esta tome posição em favor dos que não foram anistiados, através de ação judicial contra o Estado, com a argumentação da inconstitucionalidade da Lei da Anistia. Esse fato, por outro lado, parece ser mais uma manobra dos movimentos para se eximirem de arcar com despesas judiciais, nos processos de presos que poderão ter suas penas reduzidas. (ACE 4214/79. Fundo SNI. Arquivo Nacional)

A despeito da linguagem carregada de intencionalidades, os três documentos em conjunto possuem uma quantidade de informações que, sem dúvida, ajudaram a construir uma narrativa acerca da luta pela anistia e seu caráter de enfrentamento aberto ao regime durante todo o processo. No entanto, a análise documental demonstrou que existem diferentes motivações e ações no espaço temporal entre 1975 e 1983. Se, por um lado, tal documentação evidencia que os militares e os movimentos pela anistia vivenciaram tensões e conflitos, sobretudo, por conta do tipo de anistia idealizado por esses grupos, por outro lado, é possível notar algumas dinâmicas diferenciadas dentro dessa cronologia mais ampla.

\section{5-1983: as manifestações pela anistia ampla, geral e irrestrita e o olhar vigilante dos protetores da nação.}

As demandas dos movimentos pela anistia significaram para a comunidade de informações e segurança do regime, independente do momento, um objeto de atenção 
tanto pelas bandeiras levantadas, quanto pela sua capacidade de mobilizar diferentes pessoas e entidades. De modo que, por muitos meios e práticas, as atividades dos setores envolvidos com a luta pela anistia estiveram sob o olhar vigilante do regime. Em 1975, ano de surgimento do MFPA, a atenção dispensada aos movimentos pela anistia ainda era incipiente, e estava relacionada à vigilância a outros movimentos, como o estudantil. Constituiu-se cobertura a tudo o que acontecia nas universidades, principalmente USP e PUC-SP, com numerosos informes feitos pelos agentes que descreviam a rotina acadêmica, como a circulação de panfletos, cartazes pregados nos prédios e realização de seminários e debates. Na luta contra o regime, os movimentos pela anistia entendiam que era por meio da organização e conscientização junto com outros movimentos populares, associações e sindicatos que seria possível um posicionamento de resistência à política autoritária dos militares. Assim, de modo geral, num primeiro momento a questão da anistia era reivindicada por movimentos que discutiam também a volta do Estado de Direito, a redemocratização do país, melhorias nas condições de vida, entre outras.

Uma característica que pode ser notada já em 1975 e que seria uma constante durante todo o período analisado, é a preocupação com a rede de solidariedade e denúncia formada no exterior e a ligação de Therezinha Zerbini, presidente do MFPA, com grupos como a Anistia Internacional e, posteriormente, com os núcleos dos CBAs na Europa. Em um documento emitido pelo Departamento da Polícia Federal do Rio de Janeiro (DI-GB), de 26 de novembro de 1974, e com difusão para boa parte da comunidade de informações e segurança do regime, a necessidade de atenção à movimentação principalmente da Anistia Internacional é clara:

Assunto: ANISTIA INTERNACIONAL - SUBVERSÃO DA ORDEM E DEMAGOGIA (ANÁLISE POLÍTICA).

Origem: Cartazes Políticos pregados em monumentos e caixas dos correios em Bruxelas/Bélgica e 'Jornal do Brasil'.

Há, atualmente, nos grandes centros urbanos dos principais Estados do País, um processo de subversão, orientado pela esquerda extremista com a conivência de políticos frustrados e punidos pelos Atos Institucionais da Revolução de Março de 1964. Esse movimento, urdido e manipulado à socapa, vem-se ampliando, com repercussão já no exterior, com o propósito de desmoralizar as nossas Instituições, desprestigiar a autoridade constituída e combater o Governo.

(...)

Por outro lado, há cerca de 10 dias, nas ruas de Bruxelas, Bélgica, nos monumentos e caixas dos correios, estão sendo pregados cartazes 
contra o Brasil. Esses cartazes, de ordinário, são confeccionados por adeptos doutrinários do Arcebispo Dom HÉLDER CÂMARA, fora do nosso país. Conforme se verifica na foto anexa, há perfeita identidade de pontos-de-vista dos extremistas do exterior com os militantes em nosso País. Conclui-se, por conseguinte, que há absoluto entrosamento entre as facções subversivas do País com as existentes no exterior. (ACE $80323 / 74$. Fundo SNI. Arquivo Nacional)

Já em 1977, em uma visita de Thomas Hammerberg, presidente da Anistia Internacional ao Brasil, temos um documento ${ }^{15}$ detalhando as atividades dele, como a sua visita à CNBB e à Nunciatura Apostólica, onde chegou a falar dos asilados políticos brasileiros que lá estavam. Na sequência, descreveu as ideias de Hammerberg sobre Direitos Humanos e Anistia em países como Brasil, Coréia do Sul, Irã, Indonésia, etc. O agente relata que, segundo ele,

(...) a Questão dos Direitos Humanos irá pressionar cada vez mais, no mundo todo, governos de todos os tipos. Existe, inclusive, um forte sentimento de rejeição a hipocrisia: 'Votar pelos direitos humanos e contra a tortura em assembleias internacionais, e praticá-las internamente. Para Hammerberg, as declarações do governo brasileiro contrárias as torturas são 'auspiciosas', 'bons indícios', mas a anistia 'continua a receber relatórios minuciosos sobre torturas em presos políticos que provam que as promessas não estão sendo cumpridas. (50E-10-11. Fundo DEOPS/SP. Arquivo Público do Estado de São Paulo)

Em outro documento ${ }^{16}$, constam relatórios diários de todos das ações de Hammerberg no Brasil, principalmente seu encontro com Therezinha Zerbini. Além disso, todos os seus dados encontram-se igualmente anotados: nomes dos pais, local de nascimento, número do passaporte e número do quarto do hotel onde ficou hospedado. $\mathrm{Na}$ continuação, temos em anexo ${ }^{17}$ todas as reportagens que saíram sobre a visita de Hammerberg. A mesma notícia foi coberta pelos seguintes jornais: Jornal da Tarde (“Anistia Internacional quer abrir um escritório no Brasil”) em 12/11/1977; Jornal da Tarde (“Anistia: a visita de Hammerberg ao Brasil”) em 14/11/1977; O Estado de São Paulo (“Anistia: Brasil tem 213 presos políticos”) em 15/11/1977; Última Hora (“Café da manhã: o

\footnotetext{
${ }^{15}$ 50-E-10-12. Fundo DEOPS/SP. Arquivo Público do Estado de São Paulo

${ }^{16}$ 50-L-0-193. Fundo DEOPS/SP. Arquivo Público do Estado de São Paulo

${ }^{17}$ 50-L-0-195. Fundo DEOPS/SP. Arquivo Público do Estado de São Paulo.
} 
homem da Anistia") em 15/11/1977.

Nos anos seguintes, a preocupação com o reflexo das ideias vindas de fora permaneceria. Ao fazer considerações sobre a criação dos CBAs, em 1978, e as posições políticas de Ruth Escobar, uma das principais militantes pela causa da anistia, um informante do DEOPS/SP relatou:

Ruth Escobar, veio orientada pela Esquerda Internacional, a criar no Brasil um CBA, que perseguissem os objetivos das congêneres em outros países, exercendo crescente pressão sobre o governo para forçá-lo a conceder 'aberturas políticas', como primeira 'deixa' para entrarem em cena, seguindo-se após, intensa mobilização, utilizando-se de todos os artifícios possíveis, explorando todos os inesgotáveis temas que pudessem abalar a opinião pública, tentando sempre colocar em 'xeque' a autoridade do regime, e inevitavelmente, o primeiro passo a ser dado seria a libertação de todos os 'presos políticos', a Anistia para os banidos e exilados, a devolução dos direitos dos cassados, e da liberdade para, retornando ao país poderem atuar - como sempre o fizeram em outras épocas - mas agora sob a legalidade, abertamente, sem os temores da clandestinidade. (50-Zo-15381. Fundo DEOPS/SP. Arquivo Público do Estado de São Paulo)

Com efeito, os movimentos pela anistia aqui no Brasil sabiam que, para ter maior visibilidade no exterior, era necessária uma publicidade dos eventos realizados, mas também uma articulação com a rede de solidariedade e denúncia criada, principalmente em países europeus. Assim, em junho de 1979, foi realizada em Roma a "Conferência Internacional pela Anistia Ampla, Geral e Irrestrita e pelas Liberdades Democráticas no Brasil”, com o objetivo de promover um desgaste da imagem do regime, mas também potencializar a ação dos movimentos pela anistia. Esse evento representou, ainda, a articulação dos CBAs brasileiros e daqueles com sede na Europa, num momento extremamente decisivo: o governo acabara de enviar ao Congresso o projeto de lei de anistia, o que causou ampla repercussão tanto na imprensa brasileira quanto europeia para os dois eventos que aconteceram quase simultaneamente (GRECO, 2003, p. 205).

A partir dessas evidências, ou seja, da reiteração da ideia de uma ligação entre os movimentos pela anistia e os movimentos no exterior, o regime construiu um discurso que buscava legitimar seus atos, além das infiltrações e manipulações da informação numa narrativa articulada entre forma e conteúdo dos documentos. 
Ainda em 1978, em outro relatório produzido também pelo DEOPS/SP sobre a realização do "I Congresso Nacional pela Anistia" na PUC/SP, num determinado momento, o agente afirmou: "toda a equipe de representantes estrangeiros, tiveram uma atuação muito ativa dentro e fora do Congresso pela Anistia, todos estão comprometidos em divulgar dentro e fora da Europa uma campanha contra o governo brasileiro"(50-Z-0-14861. Fundo DEOPS/SP. Arquivo Público do Estado de São Paulo). Nessa mesma perspectiva, em outro relatório, produzido pelo SNI - Agência São Paulo, em 08 de novembro de 1978, ou seja, alguns dias depois da realização do I Congresso, o agente após descrever as deliberações do evento, concluiu:

Do exposto, observa-se que:

a. Existe um plano, já em execução, cujo objetivo é obter a anistia e a consequente libertação dos presos políticos brasileiros, além de possibilitar o retorno, a curto prazo, de terroristas e subversivos que se encontram banidos ou no exílio.

b. Para a consecução desse plano há interesse em sensibilizar a opinião pública nacional através de cartas, panfletos e reuniões. No mesmo sentido, no campo internacional, convidar indivíduos ligados ao setor da anistia, para que tomem conhecimento de supostas arbitrariedades que teriam sido cometidas pelos Órgãos de Segurança. (ACE 6515/81. Fundo SNI. Arquivo Nacional)

Em outro documento, também produzido pelo SNI, que data de 7 de novembro de 1978, portanto, um dia antes do apresentado acima, há também a questão do retorno dos exilados, dentro dessa perspectiva de denúncia das arbitrariedades cometidas pelo regime no exterior. No entanto, segundo o informante, houve uma preocupação com as consequências da volta sem anistia: "no que tange aos exilados, a maioria mostrou-se favorável a que fossem evitados açodamentos para o regresso tendo em vista as pressões que ainda possam surgir e até mesmo as dificuldades de emprego, no momento" (ACE 7542/80. Fundo SNI. Arquivo Nacional). Nessa mesma perspectiva, em outro relatório, dessa vez produzido pelo DEOPS/SP, e também sobre a realização do I Congresso Nacional pela Anistia há o apontamento em comum com o anteriormente citado. De acordo com ele,

No que tange aos exilados, ficou comum aos participantes, que não deveriam apressar de imediato a volta dos mesmos, pois que os mesmos encontrariam problemas dos mais diversos, como penas a cumprir, longas fichas nos órgãos de repressão e informação do país, pois que ninguém sabe quantos arquivos detem o poder para controlar os 
exilados e demais antagonistas políticos ao regime. (ACE 7542/80. Fundo SNI. Arquivo Nacional)

O interessante é perceber, a partir desses exemplos, a constituição da informação (recebimento de documentos, elaboração de relatórios detalhados, relatórios diários e arquivamento de jornais) construída pela comunidade de informações e segurança de forma a levar à criminalização do indivíduo e de quem manteve contato com ele de alguma maneira, já que todas essas pessoas também se encontravam fichadas. Segundo Aquino (2000, p. 239), "a forma pelo qual o enredo é contado se relaciona perfeitamente com o mesmo. Forma e conteúdo fazem parte de um mesmo conjunto inseparável de intenções".

Na década de 1980, a análise da documentação apontou que a lógica da desconfiança do DEOPS/SP e do SNI vai ser pautada pelo progressivo esvaziamento dos CBAs, estando a demanda da luta pela anistia mais uma vez conjugada a outras bandeiras políticas. Se, na segunda metade da década de 1970, o diálogo acontecia principalmente com o movimento estudantil, na década de 1980 os movimentos pela anistia voltam sua atenção para uma articulação com o movimento sindical e também para a perspectiva da popularização da luta, questão aprovada ainda em 1978 por ocasião do I Congresso Nacional pela Anistia.

Pensando nisso, notamos que o controle e vigilância nesses dois momentos estão relacionados não apenas com a luta pela anistia, mas com os diálogos estabelecidos entre esses movimentos considerados "subversivos". Essa característica comum, a formação dos movimentos pela anistia e o início da década de 1980, revela que o aparato de informações e segurança do regime estava atento às relações tecidas entre os diversos setores, especialmente pelo acompanhamento diário das atividades estudantis e sindicais que, invariavelmente, faziam referência à luta pela anistia. Tudo era devidamente vigiado e relatado.

Em um informe produzido pela Agência Central do SNI, em 12 de março de 1980, temos uma análise dos rumos tomados pelos CBAs nesse momento, tendo em vista a aprovação da Lei de Anistia nos moldes propostos pelo governo. Segundo ele, 
adotar como linha política geral a aproximação da Luta pela Anistia com os movimentos populares. Foram sugeridas as seguintes propostas:

- Formação de um Comitê de Apoio ao Movimento Popular contra a repressão, A justificativa para a formação deste Comitê é que, na atual conjuntura, deve-se dar ênfase às ligações com os movimentos de massas, comandos de greves, sindicatos, associações de bairros, etc.

- Esses Comitês seriam organizados dos atuais núcleos dos CBA e dariam apoio político e material aos movimentos populares.

- Ampliar as denúncias da repressão policial e da questão da prisão tutelar. (ACE 2785/80. Fundo SNI. Arquivo Nacional)

Na perspectiva do SNI, no entanto, a maioria dos documentos ressalta o caráter da continuidade da luta, a partir das campanhas pela execução da Lei de Anistia e das buscas dos familiares pelos mortos e desaparecidos. Se aquele momento foi caracterizado pela necessidade de aproximação com as classes populares, num processo iniciado ainda em 1979, seria marcado, ainda, pelo progressivo esvaziamento dos CBAs e o protagonismo cada vez maior da luta dos familiares que não haviam sido atendidos em suas demandas e reivindicações. Em maio de 1980, o SNI - Agência Rio de Janeiro elaborou uma análise no momento da realização do II Congresso Nacional pela Anistia, em novembro de 1979, buscando destacar a atuação dos familiares e o indicativo de que estes tinham a intenção de organizar uma caravana à região do Araguaia:

(...) os Movimentos pela Anistia e os familiares dos guerrilheiros estão organizando a caravana, que terá os seguintes objetivos: - chamar a atenção da opinião pública internacional e nacional sobre o fato; - colher dados sobre os participantes do movimento guerrilheiro; - cobrar do Governo os esclarecimentos julgados necessários, através de ações judiciais. (ACE 2676/80. Fundo SNI. Arquivo Nacional)

Em outros documentos, no entanto, os agentes procuraram chamar atenção para os possíveis conflitos gerados em função desse aceno dos familiares em se deslocarem até a região onde ocorreu a Guerrilha do Araguaia. Em dois documentos ${ }^{18}$, ambos produzidos no mesmo dia, 18 de julho de 1980, o destaque é o sentido conferido às discordâncias entre visões distintas sobre a realização da caravana. De acordo com esses relatórios, as agentes pastorais de Marabá, no Pará, e o advogado e presidente do CBA/SP Luiz Eduardo Greenhalg seriam os principais protagonistas desse dissenso em relação à decisão dos familiares. No entanto, o que chamou atenção, de fato, foi a

\footnotetext{
${ }^{18}$ ACE 3759/80 e ACE 9572/80. Fundo SNI. Arquivo Nacional.
} 
tentativa de descaracterizar essa iniciativa, além de supostamente isentar o regime de qualquer opinião contrária ao tema, tendo em vista que não há nenhuma menção nesse sentido.

No caso do DEOPS/SP, o destaque é dado mais para a perspectiva da necessidade de unificação dos movimentos a partir da ótica da continuidade da luta, como está expresso no título do relatório e no seu conteúdo:

Dia 29.05.80: o tema foi A CONTINUIDADE DA LUTA PELA ANISTIA, com início às 20:30 hs no sub-solo da catedral de Santo Antonio e a presença de aproximadamente 50 pessoas. A mesa que dirigiu os trabalhos foi composta da seguinte forma: Francisco Rafael (presidente do CBAPiracicaba), Luis Eduardo Greenhalgh (presidente do CBA-São Paulo), Tereza Fiel Filho (irmã de Manuel Fiel Filho), Márcia Augusta Capistrano (irmã de David Capistrano, desaparecido), Ana Dias da Silva (viúva de Santos Dias da Silva). As três senhoras foram breves em suas palavras, contando para os presentes da experiência pessoal que passaram quando membros de suas famílias foram mortos ou 'desapareceram', a luta que vem fazendo para conscientizar a população para lutar contra o regime. Greenhalgh salientou o fato de que a luta pela Anistia continua, não pode parar com a anistia parcial concedida. Ela recomeça com a anistia para os trabalhadores, bem evidenciada no $A B C$, numa anistia pelo povo brasileiro, o CBA não pode parar. As entidades civis, os movimentos populares, a busca nos cemitérios de corpos de presos que se opuseram ao regime, são algumas das formas de prosseguir com a luta. (20-C-4410909. Fundo DEOPS/SP. Arquivo Público do Estado de São Paulo)

Notamos, a partir desse relatório, que as preocupações que envolviam a comunidade de segurança e informações nessa vigilância em pleno processo de abertura se davam não apenas pela bandeira da luta pela anistia, mas pelas manifestações conjuntas entre os movimentos, evidentes na posição do advogado Luiz Eduardo Greenhalg, que advertia para a necessidade de prosseguir com a luta pela anistia articulada ao movimento sindical. Após o episódio do RioCentro, em 1981, realizou-se na Praça da Sé um “Ato Público em Repúdio aos Atos Terroristas". ${ }^{19}$ O curioso é perceber, além da descrição detalhada, os comentários feitos pelo agente que cobriu o evento.

\footnotetext{
${ }^{19}$ A convocatória para o ato fazia o seguinte chamado: "A nação vem assistindo, indignada, a ocorrência de atos impunes e vê o envolvimento de agentes do DOI-CODI do $1^{\circ}$ Exército no atentado do Rio Centro que poderia ter causado a morte de milhares de pessoas. (...) Por isso, as entidades que subscrevem esta nota convidam o povo de São Paulo para um grande ato público de protesto, uma noite de repúdio ao terror, quinta feira, dia 21, às 18 horas na Praça da Sé”. Esse panfleto foi anexado pelo SNI - Agência São Paulo juntamente com dois relatórios do DEOPS/SP. ACE 7638. Fundo SNI. Arquivo Nacional.
} 
Conforme o relato,

I - No dia 21 Mai 81 por volta de 18:30 horas realizou-se nas escadarias da Catedral da Praça da Sé um 'Ato Público em Repúdio aos Atos Terroristas', organizado pelas seguintes entidades:

-Associação Brasileira de Imprensa - S. Paulo;

-Comissão de Justiça e Paz;

-Comitê Brasileiro pela Anistia;

-Conselho Coordenador das Sociedades Amigos de Bairros;

-Movimento contra a Carestia;

-Ordem dos Advogados do Brasil;

-Partidos Políticos de Oposição;

-União Metropolitana de Estudantes Secundaristas;

-Unidade Sindical.

II - Participaram do Ato cerca de 600 pessoas.

Os oradores em suas falas se prendiam num mesmo assunto: 'exigência rápida da apuração dos culpados pela explosão da bomba no RioCentro, na Ordem dos Advogados do Brasil no Rio de Janeiro e no Jornal Tribuna da Imprensa' e 'punição rigorosa dos culpados'.

III - Notava-se a descontração dos oradores ao atacar violentamente com palavras as autoridades constituídas, falando os nomes das mesmas e tendo alguns chegado ao ponto de exigir a execução dos elementos dos DOls-CODI em Praça Pública. Havia no local faixas do Jornal Tribuna da Luta Operária, do Jornal Hora do Povo e outras com os seguintes dizeres: 'Pelo desmantelamento dos DOIs-CODI', 'Abaixo a ditadura fascista', 'Pela punição dos terroristas do DOI-CODI.

Essa capacidade de aglutinação dos movimentos configurava a ampliação da suspeição dos órgãos repressores. Esse documento é especialmente interessante porque o agente, além de fornecer os “dados técnicos" da informação, como quantidade de pessoas, entidades presentes, data, hora e local, e as palavras de ordem (muito comuns na quase totalidade dos relatórios analisados), nomeia os integrantes do regime como "autoridades constituídas" e "elementos" numa mesma frase, além de deixar claro que, em 1981, ou seja, sete anos após o início da chamada "abertura política”, a ditadura não só continuava perseguindo e vigiando os opositores ou possíveis opositores do regime como também demonstrava o quão complexas eram as relações com a comunidade de informações e segurança.

Os anos de 1978 e 1979 são marcados, então, pela capacidade de aglutinação de pessoas em torno dos eventos, cada vez mais constantes, pela anistia. Durante esse 
período, a vigilância sobre esses movimentos e seu público era de tal magnitude que ações aparentemente banais foram objeto de descrição detalhada nos relatórios dos agentes infiltrados. A lógica do máximo de informações estava relacionada a uma concepção de que era necessário promover um desnudamento do cotidiano das pessoas vigiadas e de quem mantivesse contato com elas. Nessa perspectiva, o caso que mais chama atenção é o telegrama de 1979, enviado pelo delegado de polícia do DEOPS/SP, ao II Exército / SNI / IV Comar informando que “a Livraria Capitu situada na Rua Pinheiros, N 339 está distribuindo convites para uma noite de autógrafos visando o lançamento do livro 'Anistia semente da liberdade’ de Terezinha Godoy Zerbini”. ${ }^{20}$

O interessante é perceber a movimentação, feita por esse delegado, de boa parte da comunidade de informações e segurança, através de um telegrama (meio de comunicação conhecido pela urgência do assunto) para avisar sobre uma distribuição de convites. Nesse trecho do documento notamos a preocupação em: verificar uma possível conivência da livraria com as atividades dos movimentos pela anistia; nomear a autora do livro e colocar em evidência o endereço onde estavam sendo distribuídos os convites.

Nesse sentido, inserido nessa lógica de produção de uma quantidade significativa de documentos acerca dos atos, manifestações, vigílias, etc, alguns eventos se destacaram não apenas quantidade de relatórios encontrados, mas também pela sua centralidade e capacidade de articulação. Em 27 de março de 1978, por exemplo, realizouse no teatro Ruth Escobar um ato público com o objetivo de criar um Movimento Nacional de Anistia, através da articulação de diferentes entidades e pessoas. O primeiro documento $^{21}$ foi produzido pelo DEOPS/SP e arquivado no âmbito da Divisão de Informações e Segurança. ${ }^{22}$ Intitulado Ato Público e tendo como difusão a Comunidade de Informações, é possível perceber que o agente começa relatando detalhadamente as

\footnotetext{
${ }^{20} 50-Z-130-2445$. Fundo DEOPS/SP. Arquivo Público do Estado de São Paulo.

${ }^{21}$ 50-Z-0-14.384 / 50-Z-0-14.383 / 50-Z-0-14.382 / 50-Z-0-14.381. Fundo DEOPS/SP. Arquivo Público do Estado de São Paulo.

${ }^{22}$ Esse relatório é um bom exemplo de documento produzido numa data e arquivado posteriormente. Isso porque ele data de 27/03/1978, mas só foi arquivado pela DI em 19/05/1978. Além disso, a folha que antecede o documento data de 28/03/1978. Verifica-se, então, as fases de criação e o seu posterior arquivamento.
} 
pessoas e entidades presentes ${ }^{23}$ no evento e o horário de início e término, sempre destacando esses dados com o recurso das letras maiúsculas. É possível pensar que essa era uma estratégia para facilitar o posterior fichamento dos indivíduos que participavam desses eventos, já que em boa parte dos documentos os nomes são marcados a caneta. Na sequência, a ênfase recai sobre as discussões em torno da palavra de ordem que seria uma das marcas do movimento: "PELA ANISTIA AMPLA E IRRESTRITA A TODOS OS PRESOS POLÍTICOS E PERSEGUIDOS” (50-Z-0-14382. Fundo DEOPS/SP. Arquivo Público do Estado de São Paulo). O tom da fala da presidente do MFPA, Therezinha Zerbini, também é motivo de destaque, já que segundo o agente:

A representante do Movimento Feminino pela Anistia, disse que não tinha medo, desde que há 3 (três) anos, havia encetado a luta pela anistia, e criado tal movimento, mas que as lutas pela anistia deveriam ser estruturadas tecnicamente, para evitar que tomassem porradas, e que o movimento de massas deveria utilizar-se das brechas da ditadura, e que a ditadura é como o elefante, e nós como o coelho, por isto, não podemos deixar que o elefante nos pise. (50-Z-0-14382. Fundo DEOPS/SP. Arquivo Público do Estado de São Paulo)

Sem fazer maiores considerações acerca da postura de enfrentamento proposta por Zerbini, o agente discorre sobre as deliberações e pauta das próximas reuniões com o objetivo de articular e ampliar cada vez mais o movimento, através do contato com outros setores que não estavam presentes nesse ato. ${ }^{24} \mathrm{O}$ segundo documento ${ }^{25}$, produzido pelo SNI - Agência São Paulo ${ }^{26}$, com o título Atividades do Movimento Feminino pela Anistia (MFPA) São Paulo - SP, data de 19 de Abril de 1978, ou seja, posteriormente ao produzido pelo DEOPS/SP. É possível perceber, então, que as informações contidas são oriundas do primeiro relatório produzido pela polícia política ${ }^{27}$, tendo em vista que as informações, além de serem repetidas (o que poderia indicar também a infiltração de

\footnotetext{
${ }^{23}$ De acordo com esse agente, estiveram presentes cerca de 450 pessoas nesse ato público.

${ }^{24}$ 50-Z-0-14-381. Fundo DEOPS/SP. Arquivo Público do Estado de São Paulo.

${ }^{25}$ ACE 7464/81. Fundo SNI. Arquivo Nacional.

${ }^{26}$ Esse documento tem como difusão apenas a Agência Central do SNI.

${ }^{27}$ Como destacado anteriormente, o relatório produzido pelo DEOPS/SP tinha como difusão a comunidade de informações.
} 
agentes do SNI nesse evento), são descritas com a mesma estrutura de palavras do documento anteriormente analisado.

Como exemplo, temos o trecho em que há o mesmo destaque para a intervenção de Therezinha Zerbini: "a representante do MFPA afirmou que as lutas pela anistia deveriam ser estruturadas tecnicamente e que o movimento de massas deveria utilizar-se das brechas da ditadura". Esse documento é particularmente interessante porque, além de trazer as movimentações das entidades e pessoas em torno da bandeira da anistia, há o arquivamento de uma sequência de eventos ocorridos entre março e abril de 1978, ou seja, período de construção e fortalecimento de um movimento nacional pela anistia. A conclusão do relatório apresenta um pouco a amplitude dessa campanha, já que todas as informações dos eventos fichados nesse período tem o mesmo teor:

Está sendo articulado um plano para a criação, a nível nacional, de um movimento em prol da anistia. Estão ocorrendo cisões entre as entidades que se propõem à execução desse plano. Enquanto que representantes de entidades estudantis e do COMITÊ 1 DE MAIO visam socializar o movimento, o MFPA procura manter-se alheio ao aspecto político, preferindo a idéia de continuar isolado na consecução de seus objetivos. Para tal, dispõe de núcleos em diversos Estados brasileiros, fato este que facilita a execução de uma campanha a nível nacional. A imprensa da área está explorando o tema ANISTIA, o que favorece o engajamento de diversas entidades na articulação do movimento em pauta. (ACE 7464/81. Fundo SNI. Arquivo Nacional)

Produzido pelo CIE em 29 de agosto de 1978, o terceiro e último documento ${ }^{28}$ tem como título Movimento de Anistia - MFPA e CBA, com difusão para a Agência Central do SNI, CENIMAR e CISA. Com o objetivo de fazer um registro cronológico dos eventos importantes na cidade de São Paulo, há um extenso levantamento das atividades em torno da demanda da anistia, no primeiro semestre de 1978, inclusive com os apoios de organismos internacionais à luta aqui do Brasil. São apontadas também declarações de pessoas, entidades e jornais, como o Voz Operária, que, de alguma maneira, levavam a público a bandeira da anistia ampla, geral e irrestrita. Com relação ao ato público do dia 27 de março de 1978, não é possível identificar se, assim como no documento do SNI, há influência do relatório produzido pela polícia política. Isso porque, apesar das semelhanças em muitos aspectos, principalmente na fala dos oradores, esse documento

\footnotetext{
${ }^{28}$ ACE $114085 / 78$. Fundo SNI. Arquivo Nacional.
} 
apresenta uma riqueza muito maior de informações, o que nos leva a pensar que até pela distância temporal de produção dos três documentos, nesse último há uma mobilização maior da rede de informações, tendo em vista tanto o tamanho do documento, 66 páginas, quanto o detalhamento do trabalho de vigilância.

A partir desses relatórios, portanto, encontramos uma série de informações que demonstram o olhar vigilante dos agentes infiltrados, através das detalhadas citações do que foi dito nos encontros, mas também a partir da própria lógica de fichamento. Confirma-se, assim, a existência de um projeto claramente autoritário, evidenciado não apenas pelo conteúdo, mas, principalmente, pelas terminologias utilizadas: elemento, terrorista, subversivo.

No caso do DEOPS/SP, por ocasião da realização do I Congresso Nacional pela Anistia, em novembro de 1978, todas essas questões acerca das estratégias dos militares visando um descortinamento da atuação dos movimentos pela anistia estariam contempladas, além da presença demasiada de mais de um agente cobrindo o mesmo evento. Desse modo, foi constante durante a pesquisa essa perspectiva do olhar duplo, que seria potencializada na realização desse congresso. ${ }^{29}$ Isso porque, a centralidade desse evento está na sistematização das entidades de luta pela anistia, as comissões formadas, o levantamento dos mortos e desaparecidos, além das denúncias das arbitrariedades do regime.

Assim, alguns relatórios ${ }^{30}$ são extremamente detalhados: informam o horário de início e término do evento, as pessoas participantes e suas respectivas funções. Na parte destinada aos oradores, as intervenções feitas por estes são citadas individualmente. Dessa maneira, é possível supor que as infiltrações eram técnicas que permitiam um maior conhecimento não só das ideias que circulavam nos movimentos, mas também dos componentes. Em outras análises, nesse caso produzida no âmbito do SNI, temos descrições acerca dos objetivos e perspectivas dos organizadores do evento, com o agente relatando o seguinte:

\footnotetext{
29 No fundo DEOPS/SP foi possível fazer um levantamento de pelo menos 37 relatórios de agentes infiltrados sobre o I Congresso Nacional pela Anistia.

${ }^{30}$ Dossiê 50-Z-0-14864/14863. Fundo DEOPS/SP. Arquivo Público do Estado de São Paulo.
} 
a. As resoluções aprovadas em síntese pregam: - Publicação de dossiê das denúncias; - Ampliação do CBA com criação de novos Comitês e Núcleos, aliado a intensificação da campanha em favor da anistia e a ajuda às vítimas; - Fundação de um jornal nacional pela Anistia; - Criação de um organismo nacional que coordene os movimentos pela Anistia; Homenagem aos mortos 'vítimas da repressão'; - Realização de trabalho pela Anistia junto às Igrejas; - Campanha contra a nova Lei de Segurança Nacional. (ACE 7542/80. Fundo SNI. Arquivo Nacional)

Enquanto no primeiro relatório há "apenas" uma descrição pormenorizada do evento, no segundo o informante faz uma série de observações que julgou importantes. Por outro lado, se a centralidade e importância desse evento ocasionaram a produção de uma quantidade significativa de documentos ${ }^{31}$, isso não refletiu, no caso do DEOPS/SP, em uma diversidade muito grande de reflexões por parte dos agentes infiltrados. No caso do SNI, isso é ainda mais evidente quando notamos que são poucos os documentos encontrados elaborados pelas agências desse órgão. A grande maioria diz respeito, na verdade, a relatórios produzidos pelo DEOPS/SP e que se encontram anexados compondo uma narrativa em certa medida muito restrita a análises da polícia política.

É necessário ter em vista, então, que os recortes e perspectivas apontados nesse artigo não representam a totalidade da questão que envolve as relações entre o Estado e os movimentos pela anistia. Entretanto, através da apreciação de alguns pontos diretamente relacionados com o objeto em questão, buscou-se desenvolver uma percepção das especificidades, dentro dessa cronologia mais ampla, e o mais importante, os sentidos apresentados. Essa apreciação a partir de algumas temporalidades nos levou a ter uma perspectiva mais ampla do material analisado, por meio de documentos que trazem à tona não apenas a visão dos militares, mas também o caráter da própria resistência. Assim, é fundamental compreender a procedência de cada documento, as condições de sua produção e as intencionalidades presentes, tendo em vista que esses papeis são produtos de órgãos que visavam a difamação e a construção de uma verdade intencionalmente formulada para respaldar suas ações. Nesse sentido, podemos pensar

\footnotetext{
${ }^{31}$ Temos, ainda, alguns documentos referentes à solidariedade e apoio de pessoas e entidades no exterior aos participantes do congresso. 50-Z-130-5212/50-Z-130-5210/50-Z-130-5208/50-Z-130-5207. Fundo DEOPS/SP. Arquivo Público do Estado de São Paulo.
} 
os significados dessa vigilância a partir dos diálogos entre os documentos analisados, buscando reconstituir os conflitos e interesses de um regime que, em pleno processo de abertura política, usou a violência e a suspeição como forma de manter a segurança nacional.

\section{Referências}

ANTUNES, Priscila Carlos Brandão. SNI \& Abin: uma leitura da atuação dos serviços secretos brasileiros ao longo do século XX. Rio de Janeiro: FGV, 2002.

AQUINO, Maria Aparecida de. Um certo olhar. In: TELES, Janaína (Org.) Mortos e desaparecidos políticos: reparação ou impunidade? São Paulo: Humanitas/FFLCH, 2000.

AQUINO, Maria Aparecida de; LEISTER FILHO, Adalberto; MATTOS, Marco Aurélio Vannucchi L. de; SWENSSON JR., Walter Cruz. (org.). A alimentação do leviatã nos planos regional e nacional: mudanças no DEOPS/SP no pós-1964. Família 50. São Paulo: Arquivo do Estado : Imprensa Oficial, 2002.

AQUINO, Maria Aparecida de; MATTOS, Marco Aurélio Vannucchi Leme de; SWENSSON JR., Walter Cruz. (org.). No coração das trevas: O DEOPS/SP visto por dentro. São Paulo: Arquivo do Estado; Imprensa Oficial, 2001.

ARAÚJO, Maria Paula do Nascimento. Lutas democráticas contra ditadura. In: FERREIRA, Jorge (org.). Revolução e democracia (1964 - ...). Rio de Janeiro: Civilização Brasileira, 2007.

ARQUIVO NACIONAL. Centro de Informações da Aeronáutica.

ARQUIVO NACIONAL. Divisão de Segurança e Informações do Ministério da Justiça.

ARQUIVO NACIONAL. Serviço Nacional de Informações.

ARQUIVO PÚBLICO DO ESTADO DE SÃO PAULO. Departamento de Ordem Política e Social.

BAUER, Caroline Silveira. Um estudo comparativo das práticas de desaparecimento nas ditaduras civil-militares argentina e brasileira e a elaboração de políticas de memória em ambos os países. Tese (doutorado) Universidade Federal do Rio Grande do Sul. Departamento de História. Doutorado em História. Porto Alegre: UFRGS, 2011. 
BRASIL. Decreto n. 55.194, de 10 de dezembro de 1964: aprova regulamento do Serviço Nacional de Informações. Disponível em: http://www6.senado.gov.br/legislacao/ListaPublicacoes.action?id=187003 Acesso em: $27 / 08 / 2013$.

BRASIL. Lei n. 4.341, de 13 de junho de 1964: cria o Serviço Nacional de Informações. Disponível em: http://www.planalto.gov.br/ccivil_03/leis/L4341.htm Acesso em: $30 / 08 / 2013$.

BRASIL. Lei n. 6.683, de 28 de agosto de 1979: concede anistia e dá outras providências. Disponível em: http://www.planalto.gov.br/ccivil_03/leis/L6683.htm Acesso: em 29/08/2013.

D’ARAÚJO, Maria Celina; SOARES, Gláucio Ary Dillon; CASTRO, Celso (Orgs.). A volta aos quartéis: a memória militar sobre a abertura. Rio de Janeiro: Relume-Dumará, 1995.

D’ARAÚJO, Maria Celina; SOARES, Gláucio Ary Dillon; CASTRO,Celso (Orgs). Visões do golpe: a memória militar sobre 1964. Rio de Janeiro: Relume-Dumará, 1994.

Depoimento do General Octávio Costa. D’ARAÚJO, Maria Celina; SOARES, Gláucio Ary Dillon; CASTRO, Celso (Orgs.). A volta aos quartéis: a memória militar sobre a abertura. Rio de Janeiro: Relume-Dumará, 1995.

FICO, Carlos. Como eles agiam: os subterrâneos da ditadura militar: espionagem e polícia política. Rio de Janeiro: Record, 2001.

GRECO, Heloisa Bizoca. Dimensões fundacionais da luta pela anistia: a dimensão do político ou vocação instituinte da luta pela anistia. Tese (doutorado) - Universidade Federal de Minas Gerais, Departamento de História, Doutorado em História. Belo Horizonte: UFMG, 2003. 
"En todas las dictaduras siempre hay espacios de resistencia frente a la opresión". A atuação dos movimentos pela anistia e o controle e vigilância do regime civil-militar (1975-1983)

Pâmela de Almeida Resende

Recebido em: 04/09/2013 Aprovado em: 15/11/2013

Universidade do Estado de Santa Catarina - UDESC Programa de Pós-Graduação em História - PPGH Revista Tempo e Argumento Volume 05 - Número 10 - Ano 2013 tempoeargumento@gmail.com 